\begin{tabular}{|c|c|c|c|}
\hline \multirow{3}{*}{$\begin{array}{r}\text { Case Reports in } \\
\text { Gastroenterology }\end{array}$} & Case Rep Gastroenterol 201 & & \multirow[b]{2}{*}{ Oparger } \\
\hline & $\begin{array}{l}\text { DOI: 10.1159/000448988 } \\
\text { Publisned online: October 18, } 2016\end{array}$ & $\begin{array}{l}\text { (c) } 2016 \text { The Author(s) } \\
\text { Published by S. Karger AG, Basel } \\
\text { www.karger.com/crg }\end{array}$ & \\
\hline & $\begin{array}{l}\text { This article is licensed under the } \\
\text { International License (CC BY-NC) } \\
\text { Usage and distribution for commerci }\end{array}$ & $\begin{array}{l}\text { nons Attribution-NonCommercial } 4 . \\
\text { ger.com/Services/OpenAccessLicense) } \\
\text { uires written permission. }\end{array}$ & \\
\hline
\end{tabular}

\title{
Autoimmune Pancreatitis: A Case of Atypical Radiographic Findings
}

\author{
Shawhin Karimi ${ }^{a}$ Parth Bharill ${ }^{b}$ \\ ${ }^{a}$ Department of Medicine, University of Pittsburgh Medical Center - Mercy Hospital, \\ Pittsburgh, Pa., USA; ${ }^{b}$ Division of Gastroenterology, University of Pittsburgh Medical \\ Center - Mercy Hospital, Pittsburgh, Pa., USA
}

\section{Keywords}

Autoimmune pancreatitis · Cholangitis · Prednisone $\cdot$ Rituximab $\cdot$ IGG4-RSD

\begin{abstract}
Autoimmune pancreatitis (AIP) is a rare pancreatic disorder that can present as a manifestation of a broader systemic inflammatory disease known as immunoglobulin G4-related systemic disease (IGG4-RSD). AIP is divided into two subtypes based on clinical, radiological, and histological findings. The disease can be mistaken for pancreatic cancer because of overlapping clinical and radiological findings, but early recognition can help avoid unnecessary surgery. We present a case of a 65 -year-old female with suspected acute gallstone pancreatitis found to have AIP based on serology, radiological findings, and response to steroids.
\end{abstract}

(C) 2016 The Author(s)

Published by S. Karger AG, Basel

\section{Background}

In 1961, the first case of idiopathic chronic pancreatitis with hypergammaglobulinemia suggestive of an autoimmune etiology was reported [1]. In 1995, the concept of autoimmune pancreatitis (AIP) was proposed after a case in Tokyo, Japan, was treated successfully with steroids [2]. Today, AIP is recognized as a distinct entity that is part of an emerging class of immune-mediated diseases known as immunoglobulin G4-related systemic disease (IgG4RSD). The diagnosis of AIP can be challenging, and various criteria have been published to 
aid in its diagnosis, including the latest International Consensus Diagnostic Criteria (ICDC) in 2011 [3]. The disease is further subdivided into two categories, type I AIP and type 2 AIP, based on demographics, histology, and other organ involvement.

Type 1 AIP is the more common form of the two, accounting for approximately $80 \%$ of the cases in the United States [4,5]. The histopathology is characterized by infiltration of lymphoplasmacytic cells without granulocytes and IgG4-positive plasma cells. Patients often present at an older age, and the disease generally has a predilection for males. Type 1 AIP is considered the pancreatic manifestation of the broader systemic inflammatory disorder known as IgG4-RSD with the biliary tree being the most common extrapancreatic site involved. The shared characteristic histopathological findings of lymphoplasmacytic infiltration, IgG4-positive plasma cells, and response to steroids support the association between other organ involvement and AIP.

In contrast, the histopathology of type 2 AIP is characterized by infiltration of the pancreatic ducts by neutrophils, which often leads to its destruction and/or obstruction. Type 2 AIP is also unique in its lack of extrapancreatic involvement and little or no IgG4-positive infiltrates on histology. There is also no gender predilection in type 2 AIP [6].

Though the pathogenesis of AIP is not well known, elevated levels of autoantibodies, lymphoplasmacytic infiltration, and hypergammaglobulinemia all point to an autoimmune process. Patients with AIP have nonspecific clinical findings with symptoms of obstructive jaundice being the most common clinical manifestation. It is important to note that elevated serum IgG4 levels can also occur in various other conditions such as allergic diseases and parasitic infections; however, it is still used as part of the diagnostic criteria in AIP.

Various diagnostic criteria have been created over the years in order to aid clinicians in the diagnosis of AIP, including the Mayo HISORt criteria [7, 14] and the most recent International Consensus Diagnostic Criteria (ICDC), which were introduced in 2011 [3]. Both of these diagnostic criteria have utilized specific radiological findings associated with AIP to help the diagnosis. The four major morphological patterns that have been described on CT include diffuse pancreatic parenchymal enlargement, which has been associated with 40$60 \%$ of cases , and the other three less common findings that include focal enlargement of the pancreas, a mixed pattern, and in very rare cases a normal pancreas $[8,9]$. To date, very few cases of AIP have been reported with normal radiologic findings on CT. In one case series, only 4 out of 25 reported cases of AIP demonstrated a normally appearing pancreas on CT imaging [3].

Numerous endoscopic ultrasound (EUS) findings have been reported including diffuse enlargement, hypoechoic pancreas or focal hypoechoic mass, and hyperechoic strands or foci in the parenchyma $[10,11]$. Given the nonspecific nature of these findings, EUS has generally been used to obtain histological evidence through fine-needle aspiration.

Various treatment modalities have been used in AIP, with steroids being the mainstay of therapy with generally good response to it. Immunomodulators and biologics are used to prevent relapse in patients and those who are not able to tolerate steroids. Therefore, it is essential to exclude pancreatic cancer, as numerous patients with AIP have reportedly undergone unnecessary surgery in the past [12].

We present a unique case of type 1 AIP with normal radiographic features, however, with a majority of other clinical features present. Our patient responded well with steroids but continued to have relapse and was therefore started on rituximab infusions with improvement in symptoms. 


\section{Case Presentation}

A 65-year-old African-American female with a past medical history of chronic obstructive pulmonary disease, type 2 diabetes mellitus, and Sjögren's syndrome presented to our hospital with complaints of abdominal pain associated with jaundice, dark-colored urine, and light stools for 1 week. The patient described the abdominal pain as aching, throbbing, located in the epigastric region, and radiating upward substernally. She denied any other symptoms including fever, chills, chest pain, diarrhea, or constipation. She had quit smoking 23 years ago and denied any significant weight loss, flu-like symptoms, recent ravel, alcohol use, or previous liver disease. On arrival, the patient was afebrile but tachycardic with a heart rate of $116 \mathrm{bpm}$. Physical examination revealed a soft abdomen, nondistended, tender in the epigastric region, no hepatosplenomegaly, and normoactive bowel sounds. HEENT, cardiac, pulmonary, and neurological examinations were otherwise benign.

Laboratory workup on admission revealed elevation in Total bilirubin $3.4 \mathrm{mg} / \mathrm{dl}$, alanine transaminase (ALT) $227 \mathrm{U} / \mathrm{l}$, aspartate transaminase (AST) $207 \mathrm{U} / \mathrm{l}$, alkaline phosphatase (ALK P) $203 \mathrm{U} / \mathrm{l}$, lipase $1148 \mathrm{U} / \mathrm{l}$, and a white blood cell count of $6.7 \mathrm{~K} / \mu \mathrm{l}$. Urine analysis was positive for bilirubin. Hepatitis B and C were negative. A CT of the abdomen and pelvis with contrast revealed a distended gallbladder with questionable gallstones along with mild dilatation of the common bile duct with no mass or peripancreatic inflammation (fig. 1). An MRI of her abdomen revealed a mildly distended gallbladder, mild gallbladder all thickening, sludge, and small gallstones. She was treated at that time for presumed gallstone pancreatitis.

For evaluation of jaundice, she underwent an endoscopic retrograde cholangiopancreatography (ERCP), which revealed enlarged major papilla and a distal biliary stricture (fig. 2). Sphincterotomy and brush biopsy were done and a 10-Fr stent was placed. Pathology was read as benign ductal epithelium with inflammation. She later underwent an uncomplicated cholecystectomy which showed no stones on pathology and was discharged home in stable condition.

\section{Follow-Up}

Two months later, repeat ERCP was done for stent removal at which time a partially occluded stent in the biliary tree was noted. Sphincterotomy was done with removal of the stent. Balloon sweep showed no stone or sludge. Brushings from the stricture and ampullary biopsy were again read as benign hyperplastic glandular tissue with acute surface ulceration and acute and chronic inflammation with no evidence of malignancy. Her liver function tests (LFTs) continued to be elevated with a total bilirubin $1.6 \mathrm{mg} / \mathrm{dl}$, ALT $165 \mathrm{U} / \mathrm{l}$, AST $253 \mathrm{U} / \mathrm{l}$, and ALK P $461 \mathrm{U} / \mathrm{l}$. Labs including antinuclear antibodies and smooth muscle antibodies were normal. Erythrocyte sedimentation rate (ESR) was $56 \mathrm{~mm} / \mathrm{h}$ (normal $0-30 \mathrm{~mm} / \mathrm{h}$ ). Other labs including IgG4 were elevated at $761.0 \mathrm{mg} / \mathrm{dl}$ (normal $7-89 \mathrm{mg} / \mathrm{dl}$ ) and gamma globulin, serum protein electrophoresis was $2.19 \mathrm{~g} / \mathrm{dl}$ (normal 0.70-1.6 g/dl).

EUS and ERCP were done at which time pancreatic duct stricture (fig. 3) and an oval mass were identified in the pancreas (fig. 4). The mass was hypoechoic with poorly defined borders concerning for adenocarcinoma. Fine-needle aspiration/core biopsy as well as cytology and biopsy from the biliary stricture did not reveal any malignancy but did show 120 IgG4 cells per high-power field, with approximately $70 \%$ of the IgG cells being IgG4 (fig. $5 \mathrm{~b}$ ). CA-19-9 was $19 \mathrm{U} / \mathrm{ml}$ (normal 0-35 U/ml), and ESR was elevated at $115 \mathrm{~mm} / \mathrm{h}$. The serum IgG level was noted to be 3,610 mg / $\mathrm{dl}$ (normal 700-1,600 mg /dl). 
She was started on high-dose prednisone with significant improvement in her symptoms and improvement in the stricture on ERCP leading to stent removal. Repeat labs revealed complete normalization of LFTs with total bilirubin $0.3 \mathrm{mg} / \mathrm{dl}$, direct bilirubin $<0.1$ $\mathrm{mg} / \mathrm{dl}$, AST $18 \mathrm{U} / \mathrm{l}$, ALT $35 \mathrm{U} / \mathrm{l}$, and ALK P $131 \mathrm{U} / \mathrm{l}$. IgG-4 levels also decreased to $174 \mathrm{mg} / \mathrm{dl}$. However, after approximately 1 month of therapy, the patient requested to be taken off of corticosteroids due to persistently high blood sugars and an increasingly cushingoid appearance. She was tapered off of prednisone and within a few days, she presented to the Emergency Department with complaints of subjective fever, chills, and right upper quadrant pain. She was found to be febrile with a temperature of $100.7^{\circ} \mathrm{F}$, tachycardic with a heart rate of $124 \mathrm{bpm}$, and have transaminitis with AST 667 U/l, ALT 221 U/l, and ALK P 281 U/l. She underwent repeat ERCP and was found to have a moderate segmental biliary stricture. Balloon sweeping showing no evidence of stones. A sphincterotomy was made and a 10-Fr stent was placed.

After discussion of alternative therapeutic options with the patient, a decision was made to start the patient on rituximab therapy with a prednisone taper. Eight months after beginning rituximab, the patient remains asymptomatic. Repeat IgG4 level was down to 158.4 $\mathrm{mg} / \mathrm{dl}$, and LFTs remain normalized with total bilirubin $0.5 \mathrm{mg} / \mathrm{dl}$, AST $14 \mathrm{U} / \mathrm{l}$, ALT $16 \mathrm{U} / \mathrm{l}$, and ALK P $103 \mathrm{U} / \mathrm{l}$.

\section{Discussion}

Various criteria have been developed over the years to help diagnose AIP, including the Japanese Pancreas Society (JPS) guidelines [15], Mayo HISORt criteria [4, 14], and the more recent International Consensus Diagnostic Criteria (ICDC) for AIP [3]. The latter allow for distinction between the two types of AIP and also create criteria for indeterminate imaging findings such as in our case [3]. To have a definitive diagnosis of type 1 AIP, varying strengths of collateral evidence are needed depending on imaging findings. Because our patient did not present with typical imaging findings, stronger collateral evidence was required to have a diagnosis of AIP.

We presented the case of a female with a history of type 2 diabetes mellitus and Sjögren's syndrome who initially presented with symptoms suggestive of acute gallstone pancreatitis. Even though initial imaging failed to show any diffuse or focal findings in the pancreas, the patient had serologically positive IgG4-RSD, which appears to have resulted in a persistent common bile duct stricture providing strong collateral evidence for the diagnosis of type 1 AIP. Our patient also has a history of Sjögren's syndrome with elevated anti-La (SSB) antibody at 3.7 antibody index (normal $<1.9$ ); however, prior histological confirmation could not be located. After excluding pancreatic cancer through biopsy and brushing of the pancreas, we initiated $40 \mathrm{mg}$ of prednisone daily. Subsequently, her abdominal pain was relieved and her transaminases and ALK P levels returned to normal within 7 weeks. One of the important hallmarks of AIP is its positive response to steroid therapy. Steroid therapy improves symptomatic, radiological and serological abnormalities in AIP, and discontinuing steroid therapy increases the probability of relapse of the disease $[13,16,17]$, which happened to our patient. Amelioration of inflammation in AIP with steroid therapy is not just limited to the pancreas, with the therapeutic effects extending to other organs of the body affected by the inflammatory infiltrate as well $[17,18]$. Relapse in patients treated with steroids is common, with a recent international multicenter study reporting $31 \%$ of patients with type 1 AIP experiencing relapse versus $9 \%$ of patients with type 2 AIP $[19,20]$. 
Disease relapse is common among patients with type 1 AIP with higher rates reported amongst patients who have proximal bile duct involvement or diffuse enlargement of the pancreas at presentation [19-21]. Current treatment options for IgG4-RSD include corticosteroids, immunomodulators, such as azathioprine, 6-mecrpatopurine, mycophenolate mofetil, and rituximab $[22,23]$. Rituximab is a monoclonal CD20 antibody that has been used effectively for both induction and remission in IgG4-RSD as an alternative option for patients who are intolerant to high-dose corticosteroids, have failed immunomodulator therapy, or are unable to be weaned off of high-dose corticosteroids. In one study, 10 out of 12 patients were able to achieve induction of remission with no relapse up to 2 years on maintenance therapy [23]. Our patient was unable to be weaned off of corticosteroids with a relapse at lower dosages. She was started on rituximab therapy with a subsequent taper and discontinuation of her prednisone without any further complications during an 8-month follow-up.

\section{Conclusion}

In summary, we presented a rare case of IgG4-RSD of the biliary tree and autoimmune sclerosing pancreatitis presenting with normal imaging of the pancreas. Our objective in presenting this case was to raise awareness of AIP and the diagnostic challenges it may pose. It is imperative that one always considers the diagnosis of AIP when other differentials do not provide sufficient explanation for symptoms or clinical findings. The case also supports the use of rituximab as alternative therapy in patients who are intolerant to or are unable to be weaned off of steroids.

\section{Statement of Ethics}

The authors of this article testify that this material has not been published in whole or in part elsewhere; the manuscript is not currently being considered for publication in another journal; all authors have been personally and actively involved in substantive work leading to the manuscript, and will hold themselves jointly and individually responsible for its content. Consents were obtained from all responsible parties. The authors warrant that they have not granted or assigned any rights in the article to any other person or entity. The article is copyrightable and does not infringe upon any copyright, trademark, or patent.

\section{Disclosure Statement}

The authors of this article certify that there are no relevant financial, personal, or professional relationships with other people or organizations that pose a conflict of interest, or that could potentially influence or bias the work described in the manuscript.

\section{References}

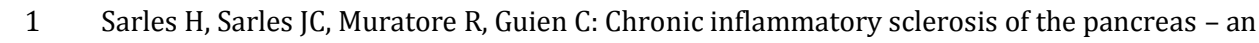
autonomous pancreatic disease? Am J Dig Dis 1961;6:688-698.

-2 Kawaguchi K, Koike M, Tsuruta K, Okamoto A, Tabata I, Fujita N: Lymphoplasmacytic sclerosing pancreatitis with cholangitis: a variant of primary sclerosing cholangitis extensively involving pancreas. Hum Pathol 1991;22:387-395. 
3 Shimosegawa T, Chari ST, Frulloni L, et al: International consensus diagnostic criteria for autoimmune pancreatitis: guidelines of the International Association of Pancreatology. Pancreas 2011;40:352-358.

-4 Sah RP, Chari ST: Autoimmune pancreatitis: an update on classification, diagnosis, natural history and management. Curr Gastroenterol Rep 2012;14:95-105.

5 Hart PA, Kamisawa T, Brugge WR, et al: Long-term outcomes of autoimmune pancreatitis: a multicentre, international analysis. Gut 2013;62:1771-1776.

6 Klöppel G: Type 2 autoimmune pancreatitis. Pancreapedia: Exocrine Pancreas Knowledge Base, 2013.

7 Chari ST: Diagnosis of autoimmune pancreatitis using its five cardinal features: introducing the Mayo Clinic's HISORt criteria. J Gastroenterol 2007;42(suppl 18):39-41.

-8 Bodily KD, Takahashi N, Fletcher JG, et al: Autoimmune pancreatitis: pancreatic and extrapancreatic imaging findings. AJR Am J Roentgenol 2009;192:431-437.

-9 Sahani DV, Kalva SP, Farrell J, et al: Autoimmune pancreatitis: imaging features. Radiology 2004;233:345-352.

10 Buscarini E, Lisi SD, Arcidiacono PG, Petrone MC, Fuini A, Conigliaro R, Manfredi G, Manta R, Reggio D, Angelis CD: Endoscopic ultrasonography findings in autoimmune pancreatitis. World J Gastroenterol 2011;17:2080-2085.

11 De Lisi S, Buscarini E, Arcidiacono PG, Petrone M, Menozzi F, Testoni PA, Zambelli A: Endoscopic ultrasonography findings in autoimmune pancreatitis: be aware of the ambiguous features and look for the pivotal ones. JOP 2010;11:78-84.

12 Manser CN, Gubler C, Mullhaupt B, Bauerfeind P: Unnecessary procedures and surgery in autoimmune pancreatitis. Digestion 2015;92:138-146.

13 Yoshida K, Toki F, Takeuchi T, Watanabe S, Shiratori K, Hayashi N: Chronic pancreatitis caused by an autoimmune abnormality. Proposal of the concept of autoimmune pancreatitis. Dig Dis Sci 1995;40:1561-1568.

14 Chari ST, Smyrk TC, Levy MJ, et al: Diagnosis of autoimmune pancreatitis: the Mayo Clinic experience. Clin Gastroenterol Hepatol 2006;4:1010-1016, quiz 934.

15 Okazaki K, Kawa S, Kamisawa T, Shimosegawa T, Tanaka M: Japanese consensus guidelines for management of autoimmune pancreatitis: I. Concept and diagnosis of autoimmune pancreatitis. J Gastroenterol 2010;45:249-265.

-16 Kamisawa T, Shimosegawa T, Okazaki K, et al: Standard steroid treatment for autoimmune pancreatitis. Gut 2009;58:1504-1507.

17 Pannala R, Chari ST: Corticosteroid treatment for autoimmune pancreatitis. Gut 2009;58:1438-1439.

-18 Kamisawa T, Yoshiike M, Egawa N, Nakajima H, Tsuruta K, Okamoto A: Treating patients with autoimmune pancreatitis: results from a long-term follow-up study. Pancreatology 2005;5:234-238.

19 Hart PA, Kamisawa T, Brugge WR, et al: Long-term outcomes of autoimmune pancreatitis: a multicentre, international analysis. Gut 2013;62:1771-1776.

20 Maire F, Le baleur Y, Rebours V, et al: Outcome of patients with type 1 or 2 autoimmune pancreatitis. Am J Gastroenterol 2011;106:151-156.

21 Sah RP, Chari ST, Pannala R, et al: Differences in clinical profile and relapse rate of type 1 versus type 2 autoimmune pancreatitis. Gastroenterology 2010;139:140-148; quiz e12-e13.

22 Hart PA, Zen Y, Chari ST: Recent advances in autoimmune pancreatitis. Gastroenterology 2015;149:39_ 51.

-23 Hart PA, Topazian MD, Witzig TE, Clain JE, Gleeson FC, Klebig RR, et al: Treatment of relapsing autoimmune pancreatitis with immunomodulators and rituximab: the Mayo Clinic experience. Gut 2013;62:1607-1615.

24 Raina A, Yadav D, Krasinskas AM, et al: Evaluation and management of autoimmune pancreatitis: experience at a large US center. Am J Gastroenterol 2009;104:2295-2306.

-25 Kamisawa T, Chari ST, Giday SA, et al: Clinical profile of autoimmune pancreatitis and its histological subtypes: an international multicenter survey. Pancreas 2011;40:809-814.

-26 Zhang L, Notohara K, Levy MJ, et al: IgG4-positive plasma cell infiltration in the diagnosis of autoimmune pancreatitis. Mod Pathol 2007;20:23-28.

27 Hamano H, Kawa S, Horiuchi A, et al: High serum IgG4 concentrations in patients with sclerosing pancreatitis. N Engl J Med 2001;344:732-738. 


\section{Case Reports in Gastroenterology

\begin{tabular}{l|l}
\hline Case Rep Gastroenterol 2016;10:581-588 \\
\hline DOI: 10.1159/000448988 & $\begin{array}{l}\text { C } 2016 \text { The Author(s). Published by S. Karger AG, Basel } \\
\text { www.karger.com/crg }\end{array}$ \\
\hline
\end{tabular}

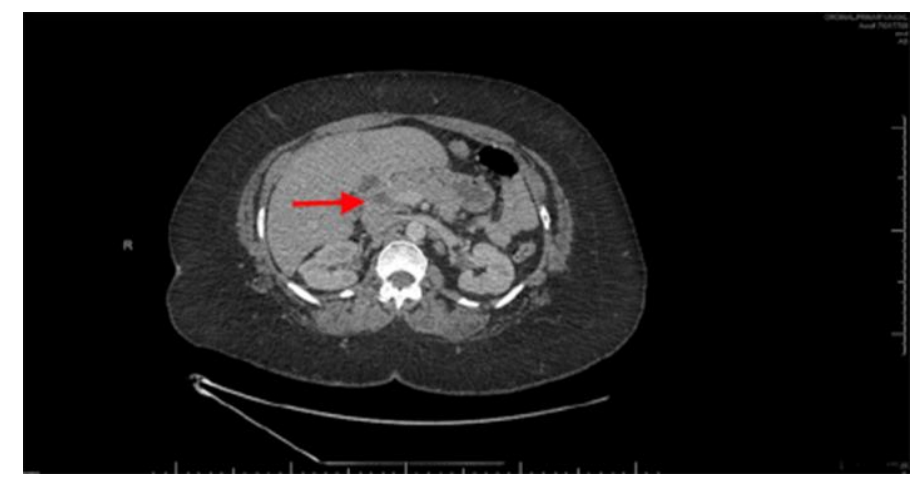

Fig. 1. CT showing mild dilatation of the common bile duct (arrow).

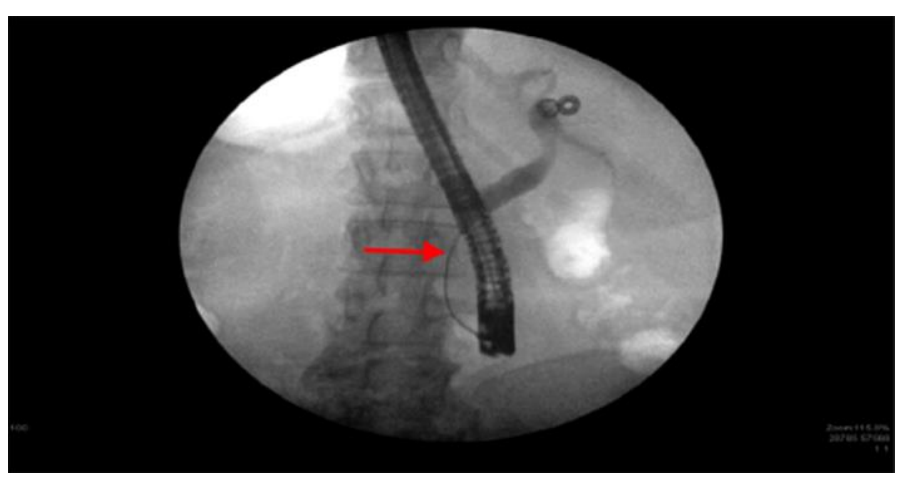

Fig. 2. ERCP showing a distal biliary stricture (arrow).

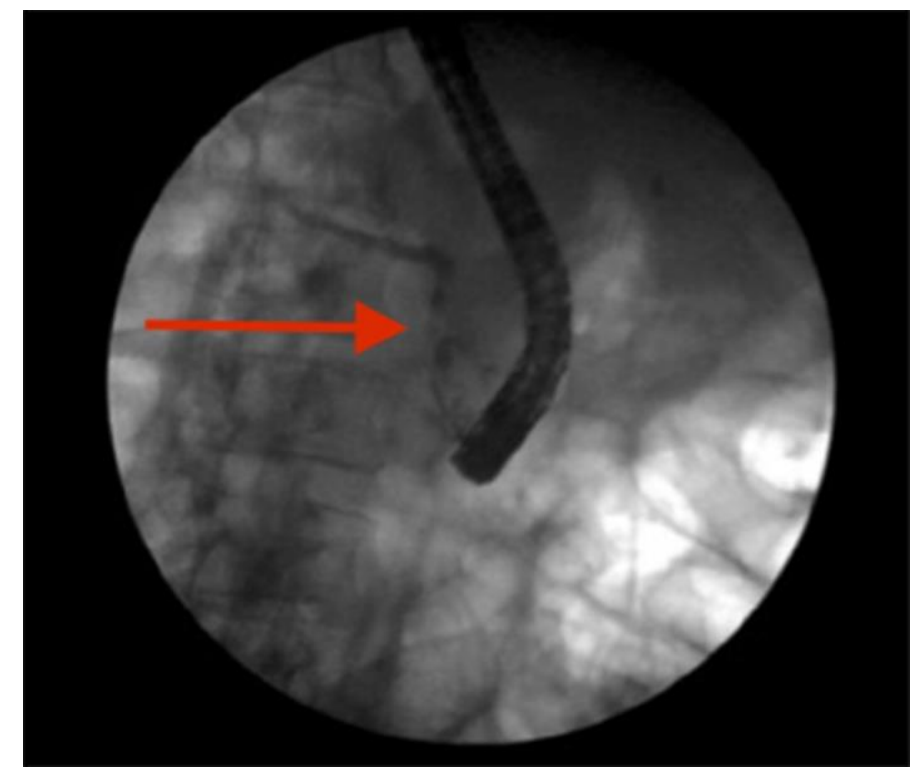

Fig. 3. ERCP revealing a stricture in the common bile duct (arrow). 


\section{Case Reports in Gastroenterology}

\begin{tabular}{l|l}
\hline Case Rep Gastroenterol 2016;10:581-588 \\
\hline DOI: 10.1159/000448988 & $\begin{array}{l}\text { @ } 2016 \text { The Author(s). Published by S. Karger AG, Basel } \\
\text { www.karger.com/crg }\end{array}$ \\
\hline
\end{tabular}

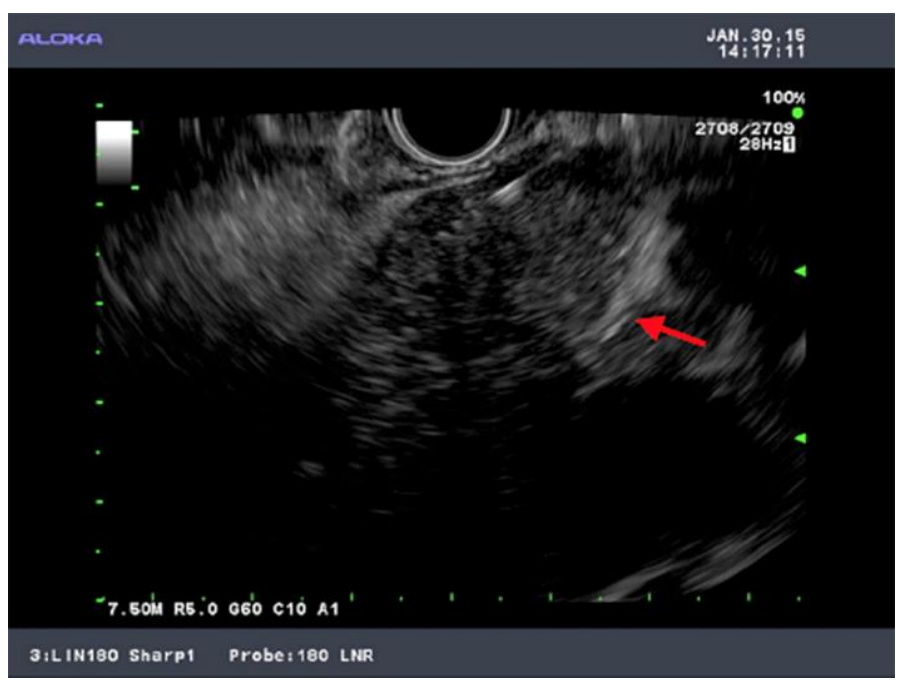

Fig. 4. EUS showing a hypoechoic mass (arrow) in the pancreas.

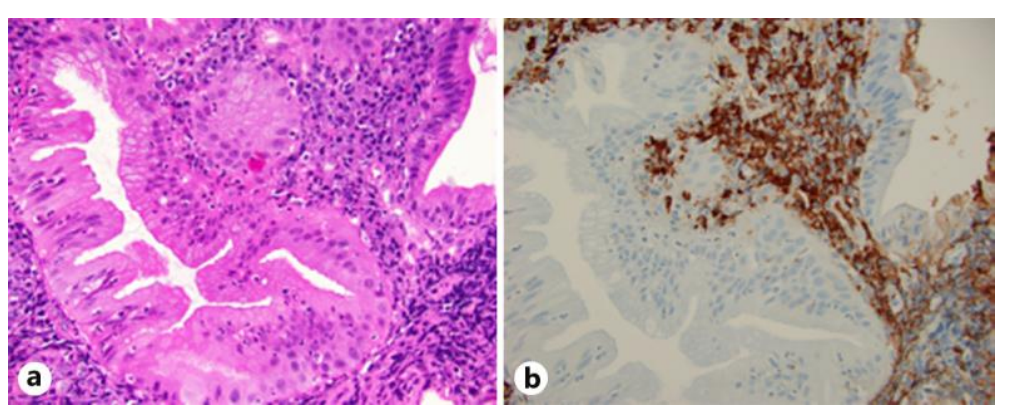

Fig. 5. a Reactive duodenal mucosa with neutrophilic infiltration within epithelium and prominent chronic inflammation within lamina propria. Hematoxylin and eosin $\times 400$. b Chronic inflammation composed of predominantly plasma cells with a high concentration of IgG4 cells. IgG4 immunostain $\times 400$. Credit: Douglas J. Hartman, MD; Department of Pathology, University of Pittsburgh Medical Center. 